Originalveröffentlichung in: Schneider, Pablo (Hrsg.): Bernini in Paris : das Tagebuch des Paul Fréart de Chantelou über den Aufenthalt Gianlorenzo Berninis am Hof Ludwig XIV., Berlin 2006, S. 376-396

THOMAS KIRCHNER

\title{
Die Lesbarkeit der Bilder. Paul Fréart de Chantelou und das Schreiben über Kunstwerke im Frankreich des 17. und 18. Jahrhunderts
}

Die Kunsttheorie war im Jahre 1665, als Paul Fréart de Chantelou sein berühmtes Tagebuch verfaßte, in Frankreich eine noch recht neue Disziplin. Und sie war eng mit der Familie Fréart de Chantelou verbunden. ${ }^{1}$ Es begann 1651. In diesem Jahr erschien in Paris erstmals Leonardo da Vincis ,Trattato della pittura'. Die von Rafael Trichet Du Fresne besorgte Edition machte den bis dahin lediglich in handschriftlichen Kopien kursierenden Text Leonardos einem größeren Publikum bekannt. Besitzer der Druckvorlage, eine Kopie des Originalmanuskriptes, war der Kunstsammler, zwischenzeitliche Mitarbeiter der königlichen Kulturverwaltung und spätere Tagebuchautor Paul Fréart de Chantelou. Im selben Jahr erschien ebenfalls bei dem Verleger Jacques Langlois eine französische Übersetzung des Textes. Angefertigt war diese von dem Bruder Chantelous Roland Fréart de Chambray. Der Band sollte für die französische Kunsttheorie von unschätzbarem Wert sein. Denn bis zu seiner Veröffentlichung war Kunsttheorie eine nahezu ausschließlich italienische Domäne gewesen. Die übrigen Länder hatten auf dem Gebiet nichts Vergleichbares vorzuweisen gehabt. In Frankreich sollte sich die Situation mit Leonardos ,Traité de la peinture“ von 1651 ändern; mit ihm war der erste Schritt gemacht. In schneller Folge erschien eine ganze Flut von nun französischen Texten, ${ }^{2}$ etwa Roland Fréart de Chambrays ,Idée de la perfection de la peinture' aus dem Jahr 1662. Wie die Malerei machte die Kunsttheorie anfänglich noch Anleihen bei den italienischen Vorbildern, spätestens mit den Bemühungen der Académie Royale de Peinture et de Sculpture ab dem Jahre 1667 kann man indes von einer spezifisch französischen Kunstheorie sprechen.

Aber bereits vor dem Erscheinen von Leonardos Traktat gab es in Frankreich eine Kunstliteratur. Literaten, Künstler, Mitglieder der königlichen Kulturverwaltung nahmen sich nach Beendigung der Religionskriege, die das kulturelle Leben nachhaltig beeinträchtigt hatten, mit zunehmender Intensität künstlerischer Fragen an. Sie verfaßten jedoch nicht Texte über Kunst, sondern vorrangig Texte über Kunstwerke. Dem Kunstwerk wurde ein Gedicht an die Seite gestellt, das es in Poesie zu übertragen versuchte, es wurde erläutert, es wurde dem nicht

1 Zur Familie Fréart de Chantelou siehe Pantin, Isabelle: Les Fréart de Chantelou. Une famille d'amateurs au XVII siècle entre Le Mans, Paris et Rome. Le Mans 1999.

2 Eine ausführliche Liste der sich mit künstlerischen und kunsttheoretischen Fragen beschäftigenden französischen Texten des 17. und frühen 18. Jahrhunderts in Germer, Stefan/Michel, Christian (Hrsg.): La naissance de la théorie de l'art en France. 1640-1720. Paris 1997 (Revue esthétique 31/32, 1997), S. 269-279. 
kundigen Betrachter durch einen Text in seinem Inhalt oder auch in seiner künstlerischen Dimension entschlüsselt, oder es wurde um Informationen ergänzt, die bildlich nicht darstellbar erschienen. Beide Bereiche, Bild und Text, gingen eine enge Verbindung ein, das Bild benötigte den Text, um sich vollends zu entfalten. Die meisten der im Folgenden untersuchten Texte liefern noch keine Kunsttheorie - auch nicht Fréart de Chantelous Tagebuchaufzeichnungen, die im Zentrum des vorliegenden Bandes stehen -, ihre Bedeutung liegt vor allem darin, daß sie sich - zuerst eher tastend, dann mit zunehmender Sicherheit - schrittweise künstlerischen Phänomenen näherten und auf diese Weise die Basis für ein umfassendes Verständnis von Kunst, für eine Kunsttheorie lieferten. Aber nicht nur die Kunsttheorie des 17. Jahrhunderts sollte auf der Verschriftlichung eines Kunstwerkes aufbauen, auch die um die Mitte des 18. Jahrhunderts entstehende neue literarische Gattung der Kunstkritik ist nur schwerlich ohne sie vorstellbar, und ebenfalls für die moderne Disziplin der Kunstgeschichte, wie sie seit dem späten 18. Jahrhundert entstand, war sie von grundlegender Bedeutung. ${ }^{3}$

Die Ergänzung von Kunstwerken durch Texte ist zuerst in einem höfischen Rahmen zu beobachten. Als man um 1600 wieder an eine Einbeziehung der Kunst in die königliche Repräsentation nachdachte, wollte man nach eingehenden Überlegungen für die anstehende prominenteste Aufgabe, die Ausstattung der Grande Galerie des Louvre, nicht an die künstlerisch anspruchsvollen Projekte von Fontainebleau aus dem 16. Jahrhundert mit Darstellungen zur klassischen Mythologie anknüpfen. ${ }^{4}$ Stattdessen schlug der Autor eines von der königlichen Administration in Auftrag gegebenen Gutachtens Antoine de Laval die künstlerisch vergleichsweise unspektakuläre Form einer Porträtgalerie vor. ${ }^{5}$ Über die politischen Gründe dieser Überlegung muß hier nicht nachgedacht werden. ${ }^{6}$ Wichtig ist für unseren Zusammenhang, daß die ganzfigurigen und vermutlich lebensgroßen Porträts der französischen Könige im Sockel der Bilderrahmen von einer Eloge ergänzt werden sollten. Der Text hatte die Aufgabe, Informationen hinzuzufügen, die das Porträt nicht vermitteln konnte, eine Aufgabe, der auch

3 Nach Fertigstellung des Manuskriptes erschien La description de l'auvre d'art. Du modèle classique aux variations contemporains. Rom/Paris 2004 (Collection d'Histoire de l'Art de l'Académie de France à Rome 4). Die hier verfolgte Argumentation wird in den Beiträgen indes nicht aufgegriffen.

4 Diskutiert wurde als mögliches Vorbild für eine moderne Ausstattung vor allem die Galerie d'Ulysse, die Francesco Primaticcio und Niccolò dell'Abate in der Zeit von etwa 1537 bis um 1570 ausgemalt hatten.

5 Laval, Antoine de: Des peintures convenables aus basiliques et palais du roy. Memes à sa gallerie du Louvre à Paris. In: ders.: Desseins de professions nobles et publiques, contenans plusieurs traictés divers et rares: Et, entr'autres, l'histoire de la maison de Bourbon, avec autres beaux secrets historiques. Paris 1605, fol. 445-453. Der Text wurde neu publiziert von Thuillier, Jacques: Peinture et politique: une théorie de la galerie royale sous Henri IV. In: Châtelet, Albert/Reynaud, Nicole (Hrsg.): Etudes d'art français offertes à Charles Sterling. Paris 1975, S. 175-205, der Text Lavals ebd., S. 195-205; zu dem Projekt siehe Kirchner, Thomas: Der epische Held. Historienmalerei und Kunstpolitik im Frankreich des 17. Jahrhunderts. München 2001, S. 31-33, 40-47.

6 Kirchner 2001, S. 33. 


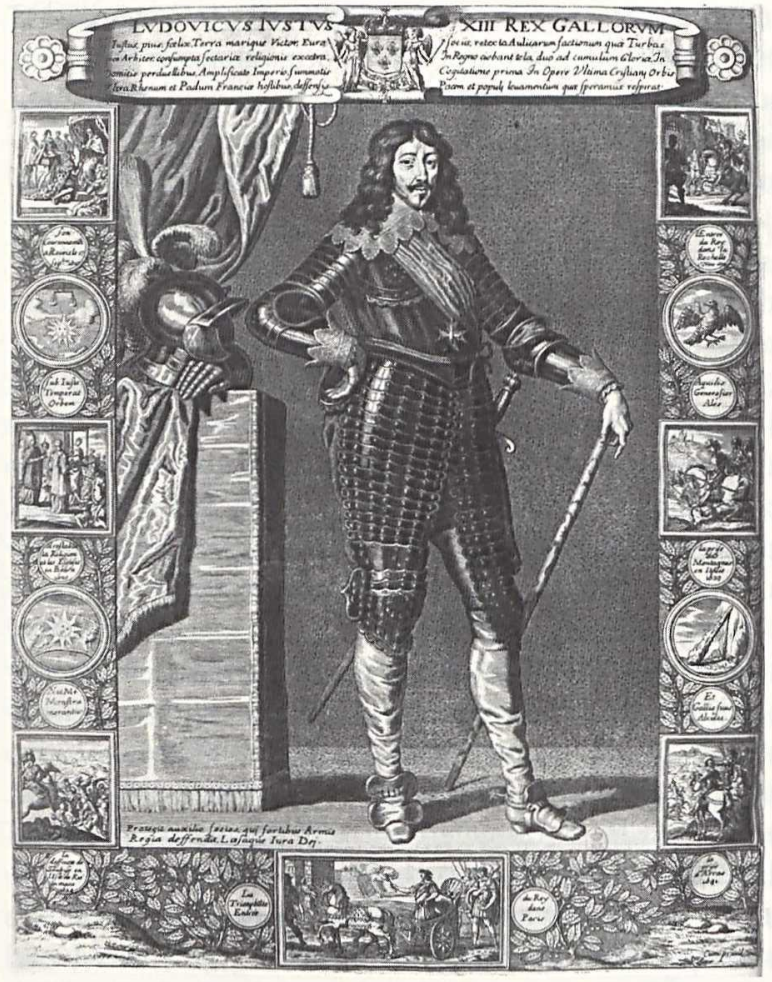

Abb. 1: François Bignon und Zacharie Heince nach Philippe de Champaigne, Ludwig der Gerechte, der XIII., König der Gallier. Illustration zu Marc Vulson de la Colombière, Les portraits des hommes illustres françois. 1650

kleinere, ebenfalls im Rahmen angebrachte Szenen aus dem Leben des jeweiligen Königs dienen sollten. Laval sah etwa für das Bildnis von Heinrich IV. eine Eloge in lateinischer Sprache von ungefähr 200 Worten vor. $^{7}$

Die Ausstattung der Grande Galerie wurde nie realisiert, man folgte dem Konzept indes weitgehend in der benachbarten Petite Galerie. Hier wurden den lebensgroßen Porträts kleinere, im Rahmen eingefügte Bildnisse von Persönlichkeiten beigegeben, die am Hofe des jeweiligen Herrschers eine wichtige Rolle gespielt hatten. Von einem begleitenden Text wissen wir aber bei dieser 1661 ausgebrannten Galerie nichts.

Daß die Ergänzung von Porträts durch einen Text durchaus üblich war, zeigt eine weitere Porträtgalerie, die dem Konzept Lavals verpflichtet war: die ,Galerie des Hommes Illustres', die der Kardinal Richelieu in seinem dem Louvre benachbarten Palais einrichten ließ. ${ }^{8}$ Zwar ist auch diese um 1637 fertiggestellte Galerie nicht mehr erhalten, jedoch vermitteln uns die Nachstiche von François

Laval 1605, hrsg. von Thuillier 1975, S. 204.

8 Siehe zuletzt Laveissière, Sylvain: Der Rat und der Mut: Die, Galerie des Hommes illustres` im Palais Cardinal - ein Selbstporträt Richelieus. In: Ausst. Kat. Richelieu (15851642). Kunst, Macht und Politik. Montreal (Museum of Fine Arts)/Köln (WallrafRichartz-Museum) 2002/03, S. 64-105; zum politischen Programm der Galerie siehe auch Kirchner 2001, S. 50-54. 
Bignon und Zacherie Heince eine klare Vorstellung vom Aufbau der von Philippe de Champaigne und Simon Vouet angefertigten Bildnisse (Abb. 1). Diese waren im Rahmen von Emblemen und einzelnen Szenen aus dem Leben der Dargestellten ergänzt, ${ }^{9}$ bekrönt wurden sie von einem in lateinischer Sprache abgefaßten Text, der die Qualitäten des Porträtierten herausstellte.

Die ,Galerie des Hommes Illustres' ist noch aus einem weiteren Grund für unsere Fragestellung von zentraler Bedeutung. Richelieu folgte bei dem Projekt dem Rat Lavals, seine Galerie durch graphische Reproduktionen einem größeren Publikum bekannt zu machen. Die aufwendige, erst nach dem Tod des Kardinals erschienene Publikation von Marc Vulson de la Colombière zeigt die Bilder mit dem kompletten Rahmenwerk und rundet die Reproduktionen von Bignon und Heince durch einen umfangreichen Text ab. ${ }^{10}$ Zwar verschiebt die Publikation die Gewichtung von Bild und Text eindeutig zugunsten des Textes, jedem Porträt ist nun neben der lateinischen Eloge eine längere Vita des Dargestellten beigegeben; einen direkten Bezug auf die Bilder nehmen indes auch diese Texte nicht, sie erläutern die Porträts nicht, sondern ergänzen diese in ihrer Aussage. ${ }^{11}$

Mit der ,Galerie des Hommes Illustres' sollte das Konzept der Porträtgalerie an sein Ende gelangen. Zunehmend wurden Konzepte bevorzugt, die in der Lage waren, auch komplexere Sachverhalte umzusetzen, die zudem künstlerische Gesichtspunkte einbezogen. Die künstlerisch unspektakulären Gattungen der Porträt- und der Landschaftsmalerei, die bis dahin die kunstpolitischen Projekte bestimmt hatten, sollten nun ersetzt werden durch die Historienmalerei, die seit Leon Battista Alberti als der Höhepunkt jeglicher künstlerischer Arbeit betrachtet wurde. Mit diesem Schritt entfiel weitgehend die Aufgabe, die Malerei mit Hilfe der Schrift um Informationen zu ergänzen, begründete doch die Historienmalerei ihren Anspruch gerade mit der Fähigkeit, selbst die kompliziertesten Sachverhalte versinnbildlichen zu können. Die Hinzufügung eines Textes wäre unter diesen Umständen als das Eingeständnis verstanden worden, dem eigenen Anspruch nicht gerecht zu werden.

Es gab indes auch eine abweichende Position, die insbesondere von den Jansenisten vertreten wurde, sich aber nicht durchsetzen konnte. Ihren deutlich-

9 Der Montrealer-Kölner Kat. zeigt eine Reihe dieser erst kürzlich auf dem Kunstmarkt aufgetauchten Rahmenszenen von der Hand des Justus von Egmont, heute im Musée des Beaux-Arts Nantes; Ausst. Kat. Richelieu (1585-1642). Montreal/Köln 2002/03, S. 82-85, 90-91, 94, Kat.-Nr. 7-9, 12, 13, 15.

10 Vulson de la Colombière, Marc: Les portraits des hommes illustres françois qui sont peints dans la galerie du Palais Cardinal de Richelieu. Avec leurs principales actions, armes, devises, et éloges latins. Ensembles les abregez historiques de leurs vies. Paris 1650; zu den weiteren Editionen siehe Kirchner 2001, S. 51, Anm. 89.

11 Angemerkt sei, daß Vulson de la Colombière auf eine Textform zurückgriff, die eine Sammlung graphischer Porträts von Texten zu den Personen begleiten ließ und dafür nicht unbedingt einer realen Porträtgalerie bedurfte. Als Beispiel sei hier etwa die Schrift von Pierre Le Moyne: La gallerie des femmes fortes. Paris 1647, angeführt. Zu diesem Typus siehe Ausst. Kat. Die Galerie der starken Frauen. La galerie des Femmes Fortes. Regentinnen, Amazonen, Salondamen. Düsseldorf (Kunstmuseum)/Darmstadt (Hessisches Landesmuseum) 1995/96. 


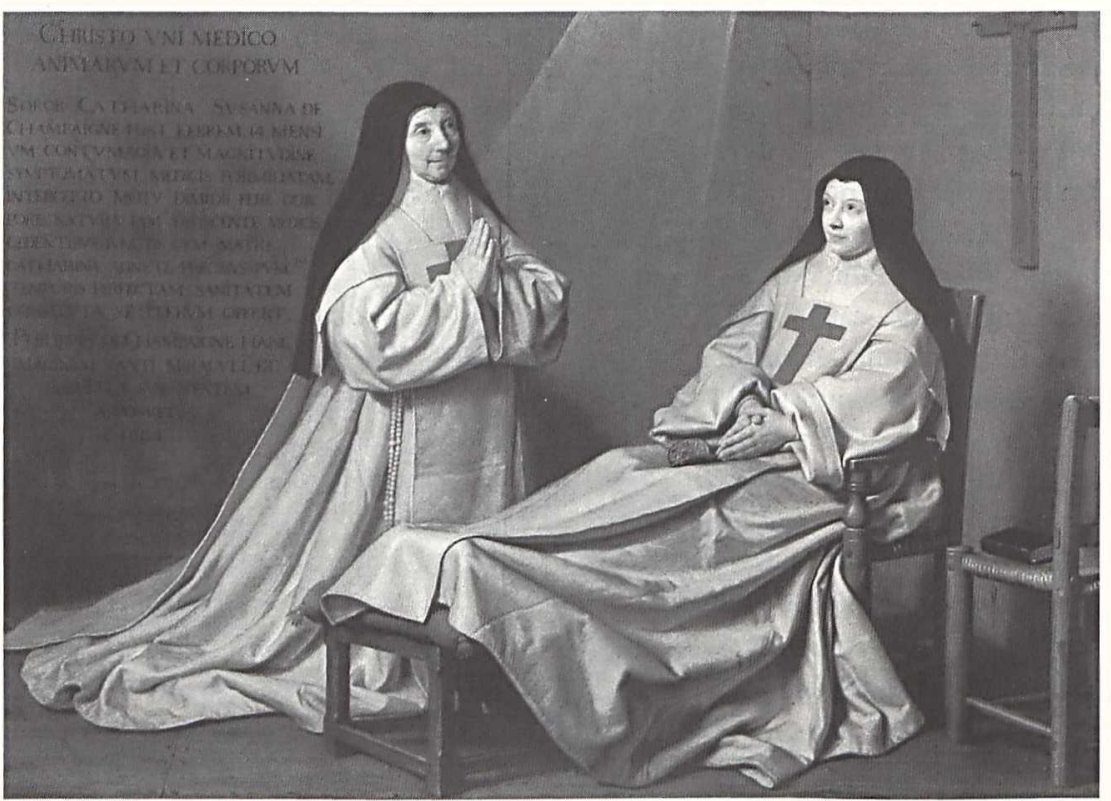

Abb. 2: Philippe de Champaigne: Exvoto. 1662. Paris, Musée du Louvre

sten Ausdruck fand diese Position in Philippe de Champaignes Exvoto (1662, Abb. 2). ${ }^{12}$ Thema ist die wundersame Heilung der Tochter des Künstlers, die als Nonne im Kloster Port Royal lebte und aus nicht erklärbaren Gründen plötzlich von einer schweren Krankheit genesen war. Nicht das Bild beschreibt indes das Wunder der Heilung, sondern der Text, der hier auf dem Bild selbst angebracht ist. Für die italienische Malerei wäre die Versinnbildung eines Wunders eine Herausforderung gewesen, alle Register zu ziehen. Champaigne dagegen verweigerte sich dieser Möglichkeit in seinem Bild. Die beiden Nonnen, die unmittelbar vor ihrer Genesung stehende Tochter des Künstlers Suzanne und die im Gebet Hoffnung schöpfende Äbtissin Mutter Agnès, sind in sich gekehrt, ein innerbildlicher Kontakt zwischen ihnen besteht nicht. Das was aus dem Gemälde ein Historienbild machen könnte, die Inbeziehungsetzung der beiden Akteure, die Wiedergabe des Wunders und dessen Ankündigung auf den Gesichtern, vermied Champaigne geradezu. Er zeigte die Porträts von zwei Personen, die kompositorisch aufeinander ausgerichtet sind, den inhaltlichen Bezug muß der Text herstellen. Der Schritt hatte geradezu ostentativen Charakter, der Künstler stellte sich einer Entwicklung entgegen, die von der Kunstakademie und der königlichen Kulturverwaltung mit Nachdruck gefördert wurde. Champaigne zeigte sich - wie auch andere Vertreter des Jansenismus - gegenüber einer Betonung künstlerischer Mittel äußerst skeptisch. Er mißtraute ihr, da in seinen Augen die Hervorhebung einer künstlerischen Dimension von dem eigentlichen Wert einer Person, von der eigentlichen Bedeutung eines Ereignisses ablenkte.

12 Zu dem Bild siehe Kirchner 2001, S. 87-89 mit weiterer Literatur. 


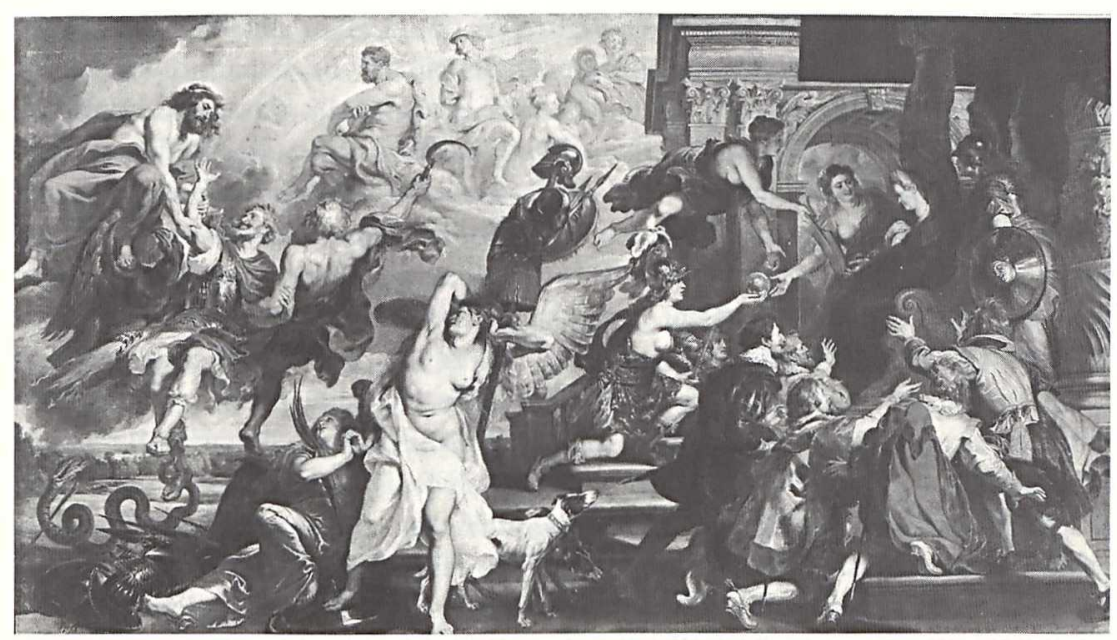

Abb. 3: Peter Paul Rubens: Apotheose Heinrichs IV. und Proklamation der Regentschaft Maria de' Medicis (14. Mai 1610). 1622-1625. Paris, Musée du Louvre

Die um 1660 bereits überholt erscheinende Position Philippe de Champaignes verdeutlicht, daß die Hinzufügung von Texten, wie wir sie bei den kunstpolitischen Projekten der ersten Jahrhunderthälfte haben beobachten können, nicht als Defizit der derart ergänzten Malerei verstanden wurde, sondern die Malerei gerade von dem befreien sollte, was sie von ihrer eigentlichen Aufgabe ablenken könnte, von einer Konzentration auf das Wesentliche, auf die Persönlichkeit eines Dargestellten.

Eine andere Strategie verfolgte die Medici-Galerie, die Peter Paul Rubens im Auftrag der Witwe Heinrichs IV. Maria de' Medici in den Jahren 1622-1625 anfertigte und in die ebenfalls der Kardinal Richelieu involviert war. Auch bei diesem Projekt soll nicht auf die politische Bedeutung eingegangen werden, hingewiesen sei indes auf die im Vergleich zu den übrigen Projekten auffallende Betonung einer dezidiert künstlerischen Dimension. ${ }^{13}$ Mit Rubens hatte man den damals berühmtesten Künstler Europas gewonnen. Er bediente sich der Historienmalerei, vermischte in den Werken zeitgeschichtliche Ereignisschilderungen mit einer mythologisch-allegorischen Erzählebene und erweiterte mit seiner neuen Bildsprache die Ausdrucksfähigkeit eines kunstpolitischen Projektes in einem starken Maße, einer Ergänzung durch einen Text bedurfte es nicht mehr (Abb. 3). Nun war es aber die komplizierte Bildsprache, die nach einer Erläuterung verlangte. Sie konnte zwar komplexe Sachverhalte bildlich umsetzen, wurde aber nicht mehr ohne weiteres selbst von einem gebildeten Betrachter verstan-

13 Die kunsthistorische Literatur hat das politische und künstlerische Konzept ausgiebig diskutiert, insbesondere seien hier Otto von Simson und Jacques Thuillier genannt. Zuletzt umfassend zu der Galerie siehe Millen, Ronald Forsyth/Wolf, Robert Erich: Heroic Deeds and Mystic Figures. A New Reading of Rubens', Life of Maria de' Medici'. Princeton 1989. 
den. So verfaßte Claude-Barthélemy Morisot unmittelbar nach Fertigstellung der Galerie eine Erklärung der einzelnen Gemälde. ${ }^{14}$ Er benannte Figur für Figur, dechiffrierte die Allegorien und die Verweise auf die klassische Mythologie und sicherte damit die Lesbarkeit der Gemälde. ${ }^{15}$ Wie seine Vorgänger beschrieb er indes nicht die Bilder, auch interessierte ihn deren künstlerische Struktur nicht. Ziel des Autors war vielmehr die Auflösung der inhaltlichen und damit der politischen Dimension der Gemälde. Ganz ähnlich ging auch der Vertraute von Maria de' Medici Mathieu de Morgues in einem kurzen, indes erst im 19. Jahrhundert veröffentlichten Text zur Galerie vor. ${ }^{16}$ Die zwei Verse, die er zu jedem Gemälde verfaßte, geben eine Lesehilfe, sie erscheinen wie ein erweiterter Bildtitel. Auch Morgues verzichtete auf die Thematisierung von künstlerischen Fragen. Anzumerken ist jedoch, daß selbst wenn Morisot und Morgues die künstlerische Dimension der Bilder von Rubens nicht ansprachen, sie diese doch aufgriffen, wenn sie ihre Erläuterungen in Versen abfaßten.

Bei den kunstpolitischen Projekten der ersten Hälfte des 17. Jahrhunderts zeichnete sich deutlich ab, daß man dem Bild allein nicht zutraute, eine gewünschte Aussage zu vermitteln, das Bild benötigte den Text. Dieser hatte zwei Aufgaben: Bei der künstlerisch unspektakulären Porträtgalerie mußte er Informationen hinzufügen, bei der künstlerisch anspruchsvollen Medici-Galerie mußte er das Verständnis der Bilder gewährleisten. Bei allen Unterschieden ist beiden Formen gemein, daß eine Verbindung von Text und Bild, derart daß der Text wirklich auf das Bild eingeht, es beschreibt und auch die künstlerische Struktur eines Werkes sprachlich zu fassen sucht, noch nicht angestrebt wurde.

Dies ist bemerkenswert, denn eine solche Verbindung wurde in einem anderen Bereich durchaus angestrebt. In einer Reihe von Gedichtsammlungen und Einzelgedichten zielten die Autoren, vornehmlich Literaten, darauf ab, einem Kunstwerk in einer dezidiert künstlerischen Form, dem Vers, zu entsprechen. Bereits durch dieses Stilmittel bewegen sich die Texte, die durchaus in einen politischen

14 Morisot, Claude-Barthélemy: Porticus medicaea. Ad illustrissimum cardinalem Richelaeum. Paris 1626. Eine zweite Auflage, die die zahlreichen Korrekturen von Rubens berücksichtigt, erschien im Jahr 1628. Der in Gedichtform abgefaßte Text umfaßt 225 Verse.

15 Ein vergleichbares Vorgehen findet man etwas später in Rom, wo Rosichino eine Erläuterung der äußerst komplizierten Ausmalung der Decke des großen Saales des Palazzo Barberini durch Pietro da Cortona verfaßte: Rosichino: Dichiaratione delle pitture della sala de' signori Barberini. Rom 1640, der Text auch bei Locher, Hubert: Das Staunen des Betrachters. Pietro da Cortonas Deckenfresko im Palazzo Barberini. In: Werners Kunstgeschichte, 1990, S. 35 f. Auch Rosichino beschränkte sich auf die Benennung der einzelnen Bildakteure, eine wirkliche Beschreibung der Decke interessierte ihn ebenso wenig wie eine Hervorhebung der künstlerischen Gesichtspunkte.

16 Morgues, Mathieu de: Vers latins sur les tableaux qui sont en la gallerie du palais de la Royne Mère du Roi (1626). In: Bulletin de la Société de l'histoire de Paris et de l'Ile-deFrance 8, 1881, S. 149-152, siehe auch Thuillier, Jacques: Rubens. La galerie Médicis au palais du Luxembourg (mit einem Quellenanhang von Jacques Foucart). Mailand/Paris 1969, S. 122-125. Zu einer Publikation des Textes sollte es aufgrund der bekannten politischen Entwicklung nicht mehr kommen. 
Kontext eingebunden sein konnten, auf einem den Kunstwerken vergleichbaren Argumentationsniveau. Wie ein Gedicht ist ein Gemälde ein Kunstprodukt. Die Gedichte sollten die Kunstwerke nicht lediglich erläutern oder ergänzen, sondern sie sollten mit sprachlichen Mitteln den Gehalt der Gemälde zum Ausdruck bringen. Die Versuche gründeten auf den antiken Beschreibungen von Kunstwerken der beiden Philostrate, die den Zeitgenossen in einer französischen Übersetzung von Blaise de Vigenère vorlagen. ${ }^{17}$ Das unmittelbare Vorbild scheint der italienische Literat Giovanni Battista Marino mit seiner überaus erfolgreichen Gedichtsammlung, Galeria' (1619/20) geliefert zu haben, der zum Zeitpunkt der Veröffentlichung am Hofe von Maria de' Medici wirkte. ${ }^{18}$ Diesem Werk folgte auch ein Literat aus der Entourage des Kardinals Richelieu, Georges de Scudéry, mit seinem ,Le Cabinet' ${ }^{\circ}$ (1646). ${ }^{19}$ In 110 Gedichten widmete sich der Autor einzelnen Kunstwerken, wobei es für Scudéry keinen Unterschied machte, ob die Werke wirklich existierten oder von ihm erfunden waren. Die Gedichte waren keine Lesehilfe für die Bilder, auch interessierte Scudéry eine umfassende Interpretation oder nur eine Beschreibung der Werke und deren Inhalte nicht. Er suchte nach einer Korrespondenz von Bild und Text und arbeitete dabei das künstlerische Moment heraus. Dessen Bedeutung wird durch die literarische Form und durch den Ort eines ,Cabinet` hervorgehoben, den der Autor für die von ihm beschriebenen Werke wählte, denn in ein ,Cabinet' werden die Werke vornehmlich wegen ihres künstlerischen Wertes aufgenommen. ${ }^{20}$

Der Kontext eines ,Cabinet', einer Kunstsammlung veränderte die Rahmenbedingungen von Kunstwerken grundlegend. Ein Kunstwerk in einer Sammlung verfolgte keine vorrangig politischen oder religiösen Ziele, selbst wenn sein Thema politischer oder religiöser Natur war. Fragen der künstlerischen Gestaltung sollten nun zum bevorzugten Gegenstand der Gespräche von Kunstsammlern, Gelehrten und Künstler werden. Insbesondere zwischen den Kunstsammlern und den Künstlern, die den neuen Markt des Sammlerbildes bedienten, entwickelte sich ein Austausch, der nicht selten eine Verschriftlichung erfuhr. Ein herausragendes Beispiel unter den Künstlern stellte dabei Nicolas Poussin dar, der wie kein anderer den noch recht neuen Typus des Sammlerbildes weiterentwickelte. ${ }^{21}$ Seine Klientel war vornehmlich in Rom und Paris ansässig, und insbesondere mit den nicht vor Ort lebenden Sammlern stand er in einem regen

17 Vigenère, Blaise de: Les images ou tableaux de platte peinture des deux Philostrates sophistes grecs de ses statues de Callystrate. Paris 1615.

18 Marino, Giovanni Battista: Galeria. O. O., o. J.; siehe dazu Albrecht-Bott, Marianne: Die Bildende Kunst in der italienischen Lyrik der Renaissance und des Barock. Studien zur Beschreibung von Portraits und anderen Bildwerken unter besonderer Berücksichtigung von G. B. Marinos, Galleria'. Wiesbaden 1976.

19 Siehe die von Christian Biet und Dominique Moncoud'huy kommentierte kritische Ausgabe der Gedichte: Scudéry, Georges de: Le Cabinet de Monsieur de Scudéry. Paris 1991.

20 Dies verhinderte indes nicht, daß auch diese Sammlung eine politische Dimension besaß; siehe Moncoud'huy, Dominique: Poésie, peinture et politique: La place de Richelieu dans ,Le Cabinet de M. de Scudéry‘. In: XVII siècle 165, 1989, S. 417-436.

21 Vgl. hierzu in diesem Band den Beitrag von Matthias Bruhn. 
brieflichen Kontakt. Auf Seiten der Sammler ist Paul Fréart de Chantelou, der spätere Autor des Tagesbuches von Berninis Paris-Aufenthalt, hervorzuheben, er ist der Adressat zahlreicher Schreiben Poussins. Die Briefe, vornehmlich in den dreißiger und vierziger Jahren verfaßt, reagierten auf die Unsicherheit, wie mit einer in Frankreich noch recht unbekannten, dezidiert künstlerischen Dimension umzugehen war.

Zwei Schreiben stechen in diesem Zusammenhang besonders hervor: der Brief vom 28. April 1639 zur Mannalese und der berühmte ,Modusbrief" vom 24. November 1647. Der Brief zur Mannalese enthält eine Art Leseanleitung des Bildes: „[...] ich glaube, Sie erkennen leicht, welches diejenigen [Figuren] sind, die ausharren, die bewundern, diejenigen, die Mitleid haben, die aus Mildtätigkeit handeln, aus Notwendigkeit, aus dem Wunsch, sich zu ernähren, Trost zu spenden oder aus anderen Gründen, denn die sieben ersten Figuren auf der linken Seite sagen Ihnen all das, was hier beschrieben ist, und der Rest ist von derselben Art: Lesen Sie die Geschichte und das Gemälde, um zu wissen, ob jeder Gegenstand dem Thema angemessen ist. Und wenn Sie, nachdem Sie dies mehr als einmal berücksichtigt haben, eine gewisse Genugtuung verspüren, sagen Sie es mir bitte, ohne etwas zu verschleiern, so daß ich mich darüber freuen kann, Sie beim ersten Mal, das ich die Ehre hatte, Ihnen zu dienen, zufriedengestellt zu haben." 22

Ein Gemälde kann wie ein Text gelesen werden, wenn es auch ungleich komplexer ist und eine mehrfache Lektüre verlangt. Poussin entschlüsselte jedoch nicht die unterschiedlichen Leseweisen und die jeweils zu erzielenden Ergebnisse. Er erläuterte nicht das Bild, benannte nicht die Textgrundlage und seine Bedeutung, erklärte die einzelnen Figuren und deren Funktion nur andeutungsweise und beispielhaft. Das anzumerken, was bei den Beschreibungen der in einen politischen Kontext eingebundenen Werke üblich war, schien ihm nicht notwendig, er konnte voraussetzen, daß sein Auftraggeber den Inhalt des Bildes auch ohne seine Hilfe verstand. Worauf Poussin den Adressaten seines Briefes mit seiner Leseanweisung aufmerksam machte, ist vielmehr die spezifisch künstlerische Dimension der Mannalese und die Vorgehensweise des Betrachters, diese Dimension zu erschließen.

Dieses Anliegen wird noch deutlicher im ,Modusbrief ${ }^{\natural}$. Poussin reagierte darin auf eine Beschwerde von Chantelou, dem eine Auffindung des Moses, die der Künstler für den Pariser Sammler Jean Pointel gemalt hatte, besser gefiel als die Priesterweihe aus der Sakramenteserie, die er soeben erhalten hatte.

22, ,[...] je crois que facilement vous reconnaîtrez quelles sont celles [figures] qui languissent, qui admirent, celles qui ont pitié, qui font action de charité, de grand nécessité, de désir de se repaître, de consolation et autres, car les sept premières figures à main gauche vous diront tout ce qui est ici écrit et tout le reste est de la même étoffe: lisez l'histoire et le tableau, afin de connaître si chaque chose est appropriée au sujet. Et si, après l'avoir considéré plus d'une fois, vous en aurez quelque satisfaction, mandez le moi, s'il vous plaît, sans rien déguiser, afin que je me réjouisse de vous avoir contenté pour la première fois que j'ai eu l'honneur de vous servir." Nicolas Poussin an Paul Fréart de Chantelou, 28.4 1639. In: Blunt, Anthony (Hrsg.): Nicolas Poussin, Lettres et propos sur l'art. Paris 1989, S. 45-46. 
„Wenn das Bild der ,Auffindung des Moses im Nil [...] Sie mit Liebe erfüllt hat, ist dies ein Beweis dafür, daß ich es mit mehr Liebe als Ihre Bilder gemalt habe? Sehen Sie nicht, daß die Natur des Themas und Ihre eigene Stimmung diese Wirkung bedingen, und daß die Themen, die ich für Sie bearbeite, in einer anderen Weise dargestellt werden müssen. Hierin liegt die ganze Kunst der Malerei. Verzeihen Sie mir die Freiheit, wenn ich Ihnen sage, daß Ihr Urteil über meine Werke voreilig war. Gut zu urteilen ist sehr schwer, wenn man nicht große Theorie und Praxis miteinander verbindet. Wir dürfen nicht allein mit unserem Geschmack urteilen, sondern mit der Vernunft. Aus diesem Grund will ich Sie über eine wichtige Tatsache unterrichten, aus der Sie ersehen, was man bei der malerischen Wiedergabe von Themen berücksichtigen muß." 23

Poussin mußte hier deutlicher werden als im Brief zur Mannalese, da sein Sammler offensichtlich eine für ihn zentrale künstlerische Frage nicht verstanden hatte. Und so erteilte er Chantelou eine Nachhilfestunde, er rügte dessen voreiliges, ja vorlautes Urteil, vor allem aber wies er seinem Auftraggeber den Weg zum Verständnis eines Kunstwerkes. Der Sammler forderte die schriftliche Instruktion zumindest im Zusammenhang mit der Priesterweihe regelrecht ein. Und der Künstler kam diesem Wunsch gerne nach. Die Verschriftlichung gewährleistete, daß die Bilder in der intendierten Form gelesen wurden und die Leistung des autonomen Künstlers'deutlich wurde. Denn nicht der Auftraggeber schrieb hier dem Künstler ein Kunstwerk, dessen Gestaltung und Gehalt vor, sondern der Künstler instruierte seinen Auftraggeber, wie er sich dem von ihm erworbenen Werk zu nähern hatte. Der Künstler ist der Gebende, nicht der Auftraggeber. Die Briefe umkreisen dieses neue Verhältnis von Auftraggeber und Künstler. Und Poussin konnte sicher sein, daß seine Ideen nicht nur vom Adressaten seiner Schreiben wahrgenommen, sondern von diesen an einen größeren Kreis weitergeleitet wurden. So zitierte etwa André Félibien in seinen, Entretiens sur les ouvrages des plus excellens peintres anciens et modernes' ausgiebig aus den Briefen Poussins an Chantelou, die er nur vom Adressaten erhalten haben kann.

23 „Si le tableau de ,Moïse trouvé dans les eaux du Nil [...] vous a donné dans l'amour, est-ce un témoignage pour cela que je l'aie fait avec plus d'amour que les vôtres? Voyez vous pas bien que c'est la nature du sujet qui est cause de cet effet, et votre disposition, et que les sujets que je vous traite doivent être représentés par une autre manière. C'est en cela que consiste tout l'artifice de la peinture. Pardonnez à ma liberté si je dis que vous vous êtes montré précipiteux dans le jugement que vous avez fait de mes ouvrages. Le bien juger est très difficile, si l'on n'a cet art grande théorie et pratique jointes ensemble. Nos appétits n'en doivent pas juger seulement, mais la raison. C'est pourquoi je vous veux avertir d'une chose d'importance, qui vous fera connaître ce qu'il faut observer en la représentation des sujets qui se dépeignent.“ Nicolas Poussin an Paul Fréart de Chantelou, 24.11.1647. In: Blunt (Hrsg.) 1989, S. 134-135. Zum ,Modusbrief" siehe zuletzt den Kommentar von Thomas Kirchner in: Gaehtgens, Thomas W. I Fleckner, Uwe (Hrsg.): Historienmalerei. Berlin 1996 (Geschichte der klassischen Bildgattungen in Quellentexten und Kommentaren, Bd. 1), S. 145-147 (Übersetzung unter Benutzung der Übersetzung von Jan Białostocki). 
Die Briefe Nicolas Poussins an seine Pariser Auftraggeber sind für die französische Kunst von großer Bedeutung. Zum ersten Mal wurde in ihnen eine künstlerische Dimension am Gegenstand konkret benannt. Damit bildeten sie eine wichtige Voraussetzung für die späteren Bemühungen der königlichen Akademie um eine schriftliche Fixierung von Regeln für die künstlerische Arbeit. Sie fanden aber auch Eingang in die Beschreibungen von in einen Repräsentationszusammenhang eingebundenen Werken, denn mit André Félibiens Schriften für den Finanzminister Nicolas Fouquet und für Ludwig XIV. wurde zunehmend deren künstlerischer Wert angesprochen. Der Historiograph reagierte damit auf eine Entwicklung seit der Mitte des 17. Jahrhunderts, bei den repräsentativen Ausstattungsprojekten schrittweise auch künstlerische Gesichtspunkte zu berücksichtigen. ${ }^{24}$

Die erste Schrift, die Félibien 1660 im Auftrag Fouquets verfaßte, ,De l'origine de la peinture, et des plus excellens peintres de l'antiquité. Dialogue', stieß bei dem Minister auf Kritik. ${ }^{25}$ Der Autor behandelte in dem Text ausführlich zentrale Fragen der zeitgenössischen Kunst unter Bezug auf die antike Malerei. Die Bemerkungen zu Fouquets Prestigeprojekt, dem aufwendigen Schloßbau von Vaux-le-Vicomte, in der Mitte des Bandes wirken dagegen wie ein lästiges Pflichtprogramm. Sie sind im Unterschied zu den Erläuterungen der künstlerischen Fragen recht allgemein gehalten. Das Schloß und seine Ausstattung wird zwar in den höchsten Tönen gelobt, nun habe man endlich in Frankreich das Niveau der italienischen Kunst erreicht; der Autor benennt indes weder einen Raum noch ein Gemälde, und auch den Künstler erwähnt er nicht. Er wolle - so begründete er dieses Vorgehen - nur ungerne über lebende Künstler sprechen, er ziehe es vor, seine Ansichten an Hand von Werken bereits verstorbener Künstler aufzuzeigen.

Félibien hatte sich in der Gattung vergriffen. Er hatte eine kunsttheoretische Studie vorgelegt, die bereits in wesentlichen Punkten die Fragestellungen der ,Entretiens' formulierte. Fouquet erwartete jedoch, daß der Historiograph, wie bis dahin bei entsprechenden Texten üblich, unmittelbar Bezug auf die Ausmalungen seines Schlosses nahm und über die künstlerischen Fragen nicht deren politische Botschaft vergaß. Diesem Wunsch kam der Autor in zwei Texten nach, die er unmittelbar nach der Erstlingsschrift für Fouquet in Briefform publizierte. ${ }^{26}$ In ihnen beschrieb er ausführlich die Deckenausmalung von zwei Räumen des Schlosses, des Musensaales und des Herkulessaales. Félibien folgte ganz der Aufgabenstellung der Beschreibung eines offiziellen Ausstattungsprogramms, wenn er die einzelnen Szenen benannte, die Figuren entschlüsselte

24 Siehe hierzu Kirchner 2001, S. 154-168, 233-256.

25 Félibien, André: De l'origine de la peinture, et des plus excellens peintres de l'antiquité. Dialogue. Paris 1660. Von der Unzufriedenheit des Auftraggebers berichtet der Autor selbst in seiner nächsten Schrift für Fouquet, ders.: Deux lettres sur Vaux-le-Vicomte. O. O., o. J., 1. Brief, S. 1. Zu ,De l'origine' siehe Germer, Stefan: Kunst-Macht - Diskurs. Die intellektuelle Karriere des André Félibien im Frankreich von Louis XIV. München 1997, S. 140-142 und Kirchner 2001, S. 245.

26 Félibien o. J. Zu der Schrift siehe Germer 1997, S. 149-161 und Kirchner 2001, S. 233-239. 


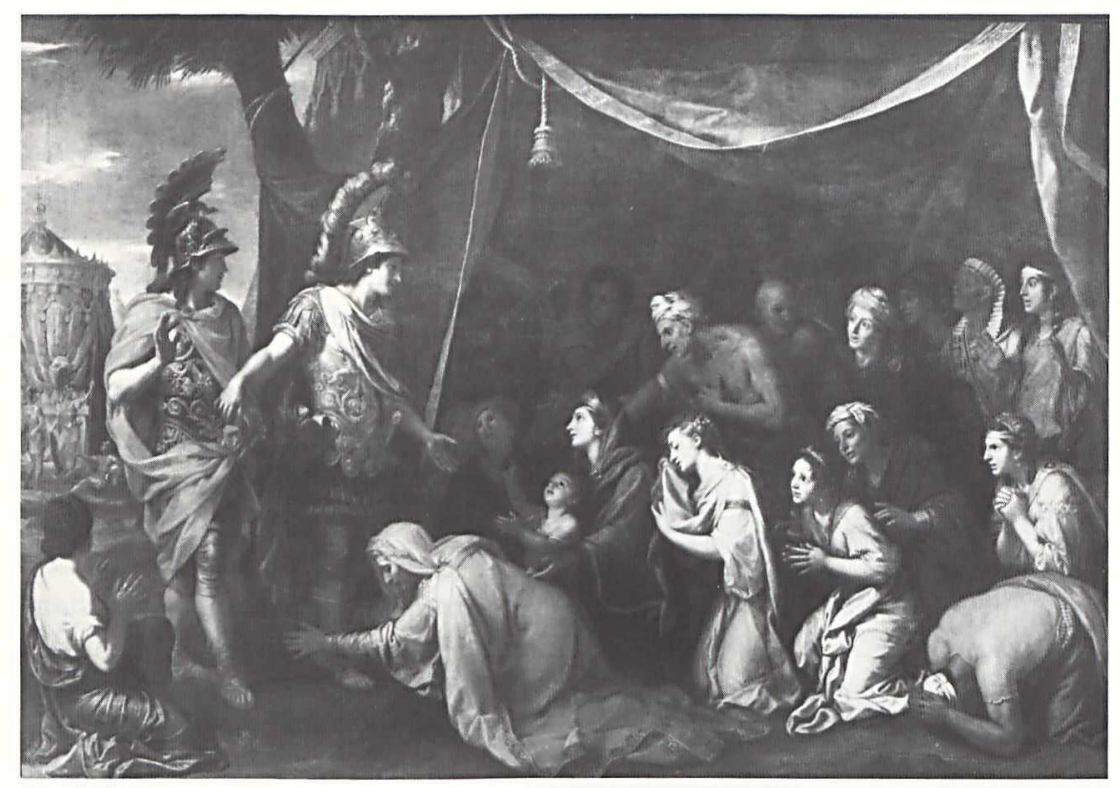

Abb. 4: Charles Le Brun: Das Zelt des Darius. 1660/61. Versailles, Musée national du château

und damit die Lesbarkeit der Darstellungen gewährleistete. Er beließ es aber nicht dabei, er lieferte auch eine Interpretation der politischen Aussage, und mit besonderer Aufmerksamkeit widmete er sich der künstlerischen Bedeutung der Deckenausmalung. Das war neu. Der soeben aus Rom zurückgekehrte Autor verband die klassische Aufgabe der inhaltlichen Erläuterung eines in einen kunstpolitischen Kontext eingebundenen Kunstwerkes mit der Herausarbeitung einer spezifisch künstlerischen Dimension, wie sie etwa Poussin in seinen Briefen seinen Gemälden angedeihen ließ. Nicht zufällig erscheint, daß sich Félibien für die neue Form der Bildanalyse der Briefform bediente. Der Bezug zu den Briefen Poussins mag sich auch den Zeitgenossen eingestellt haben, die Wahl dieser Textsorte bot sich wohl vor allem an, da es für das neue Konzept Félibiens noch keine anerkannte Schriftform gab und der Brief als eine vergleichsweise offene, wenig reglementierte literarische Gattung den größten Freiraum bot.

Félibien verfolgte sein Konzept auch nach der Verhaftung seines Auftraggebers Fouquet und seinem Wechsel zur königlichen Administration weiter. Die konsequenteste Ausformulierung fand es in der 1663 erschienenen Beschreibung von Charles Le Bruns Zelt des Darius. ${ }^{27}$ Das 1660/61 entstandene Gemälde (Abb.4) stand am Anfang von Ludwigs XIV. Regierung, es wurde allgemein nicht nur als gelungene Glorifizierung des jungen Königs betrachtet, sondern

27 Félibien, André: Les reines de Perse aux pieds d'Alexandre. Paris 1663. Zu der Schrift siehe René Démoris: Peinture et histoire: Félibien et la stratégie du récit historique au siècle de Louis XIV (d'après, Les Reines de Perse aux pieds d'Alexandre'). In: Bessière, Jean (Hrsg.): Récit et histoire. Paris 1984, S. 23-55; Germer 1997, S. 208-218 und Kirchner 2001, S. 278-283. 
auch als das zentrale Kunstwerk seiner Epoche, mit dem es endlich gelungen sei, der italienischen Kunst Paroli zu bieten, diese gar zu überbieten. Entsprechend standen im Mittelpunkt von Félibiens für die französische Kunstliteratur fundamentalem Text nicht mehr die vergleichsweise einfache Entschlüsselung des Bildes und die Erläuterung von dessen politischer Bedeutung, sondern eine detaillierte Beschreibung, deren Ziel die Herausarbeitung der künstlerischen Qualität des Gemäldes war. Nie zuvor war ein einzelnes Gemälde derart eingehend analysiert worden. Der Autor beschrieb Figur für Figur, analysierte jeden Gesichtsausdruck und die mehrschichtige Narration des Bildes. Er untersuchte die Lichtführung als eine Möglichkeit der Hierarchisierung der Bildakteure und die Farbe als ein wichtiges kompositorisches Mittel, das die Figuren in ein übergreifendes Netz einbinde. Félibien sah in dem Bild die Trennung von (künstlerischer) Form und (politischem) Inhalt überwunden, die künstlerischen Mittel Farbe und Lichtführung harmonierten in vollkommener Weise mit der Bilderzählung.

Damit schien die Form gefunden, in der mit im königlichen Auftrag entstandenen Werken umzugehen war. Und Chantelou, der wie Félibien die Diskussionen in der Surintendance des Bâtiments genauestens kannte, folgte diesen Vorgaben. Ja, er konnte sich in seinem Unternehmen durch den abschließenden Satz von Félibiens Text beflügelt fühlen, daß es nun an der Zeit sei, den König nicht mehr vermittelt durch die Taten von in vergangenen Epochen lebenden Herrschern zu glorifizieren, sondern ihn unmittelbar ins Zentrum der staatlichen Repräsentation zu stellen. ${ }^{28}$ Mit diesen Überlegungen zeichnete sich eine neue Ära in der Kulturverwaltung ab, die mit dem Namen Jean-Baptiste Colberts verbunden ist, der das Kulturressort offiziell am 1. Januar 1664 übernahm. Und es war fraglos Chantelous Wunsch, in dieser neuen Kulturverwaltung eine Position zu finden. Die Möglichkeit stellte sich im Zusammenhang mit Giovanni Lorenzo Berninis Paris-Aufenthalt im Sommer $1665 .{ }^{29}$ Chantelou wurde dem Künstler als persönlicher Adjutant und als Verbindungsmann zur Kulturverwaltung und zum Hof zugewiesen. Er begleitete den Künstler jeden Tag und hatte damit genauesten Einblick in dessen Arbeit. Was er dabei erfuhr, hielt er in einem Tagebuch fest, von dem sich nicht mehr eindeutig klären läßt, zu welchem Zweck es verfaßt wurde. Sicher scheint nur, daß es nicht dem privaten Gebrauch seines Verfassers diente. ${ }^{30}$

Nun ist unübersehbar, daß Chantelou mit dem Tagebuch sehr persönliche Pläne verfolgte. Immer wieder strich er seine Leistung heraus, stellte er seine Kompetenz unter Beweis, sonnte er sich in der Wertschätzung des berühmtesten Künstlers seiner Zeit. Und auch seine Familie vergaß er darüber nicht. Geschickt führte er im Tagebuch seinen Bruder Roland Fréart de Chambray ein, dessen Fähigkeiten er häufig hervorhob. Die lobenden Worte Berninis sind wie ein

28 Félibien 1663, S. 33-34.

$29 \mathrm{Zu}$ Berninis Paris-Aufenthalt siehe Gould, Cecil: Bernini in France. An Episode in Seventeenth-Century History. London 1981.

30 Siehe hierzu die Einleitung von Milovan Stanić zu der von ihm herausgegebenen Neuedition des Tagesbuches: Fréart de Chantelou, Paul: Journal de voyage du cavalier Bernin en France. Paris 2001, hier S. 29-32. 
Abb. 5: Giovanni Lorenzo Bernini: Porträtbüste Ludwigs XIV. 1665. Versailles, Musée national du château

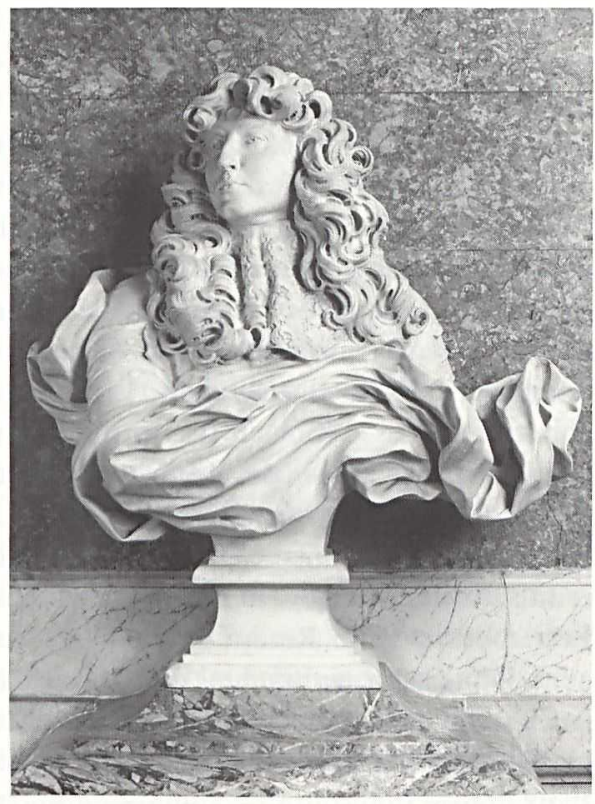

Empfehlungsschreiben für eine Position der beiden Brüder in der Surintendance des Bâtiments. So war das Tagebuch wohl als eine Art Mémoire für den Gebrauch der Surintendance gedacht, vermutlich plante sein Autor auch, es in der einen oder anderen Form zu publizieren. Im Laufe von Berninis Paris-Aufenthalt mußte Chantelou jedoch schmerzlich feststellen, daß die Autorität seines vermeintlichen Fürsprechers deutlich schwand und damit auch seine Chance auf eine erhoffte Position. Der Text weist mehrere Phasen der Überarbeitung auf, die darauf schließen lassen, daß Chantelou auch nach dem Scheitern Berninis in Frankreich den Plan einer Edition nicht völlig aufgegeben hat.

Wie ging Chantelou nun in seinem Text mit Kunstwerken um? Bei der Beantwortung dieser Frage sollen nicht so sehr die zahlreichen Passagen interessieren, in denen der Tagebuchschreiber von Berninis Kommentaren zu einzelnen Kunstwerken berichtete, seien diese nun Sammlerstücke, wie Poussins Bilder in Chantelous eigener Sammlung, oder in einen offiziellen Kontext eingebunden gewesen, wie Pierre Mignards Ausmalung der Decke von Val-de-Grâce. Die Bemerkungen sind jeweils nur recht kurz und für unseren Zusammenhang wenig aufschlußreich. Sie zeigen zwei Kunstgelehrte, die sich gegenseitig ihren Sachverstand beweisen. Anders sieht es hingegen bei der Beschreibung der Arbeiten aus, die im Zentrum von Berninis Aufenthalt standen, die Louvreplanungen und die Büste Ludwigs XIV. (Abb. 5). Insbesondere bei letzterer beobachtete Chantelou die Entwicklung Schritt für Schritt, er beschrieb die inhaltlichen Aspekte der Büste in Verbindung mit der künstlerischen Form, die diese Inhalte erst zum Ausdruck bringt, und ging dabei über den Text von Félibien zu Le Bruns Zelt des Darius deutlich hinaus. Er übertrumpfte den königlichen Historiographen geradezu, denn er konnte die Verbindung von künstlerischer Form und politischem Inhalt 
bereits am Entstehungsprozeß der Büste aufzeigen und nicht erst, wie Félibien, am fertigen Werk. Chantelou scheint dem Kunstwerk wesentlich näher, die vermeintlich authentische Beschreibung eines Tagebuches unterstreicht seine Zeugenschaft. Und noch stärker als Félibien unterlegte er seinen Ausführungen ein modernes Künstlerbild, wie er es den Briefen Poussins hatte entnehmen können. Zwar betonte der königliche Historiograph immer wieder die Fähigkeiten Le Bruns, auch hob er die Wertschätzung hervor, die der König dem Maler entgegenbrachte, Chantelou beschrieb aber Bernini als einen autonomen Künstler, der, auch wenn er im Auftrag der Kulturverwaltung arbeitete, bei der Büste ausschließlich seinen eigenen künstlerischen Intentionen folgte. Chantelou war damit im gewissen Sinne fortschrittlicher als Félibien, für den Le Brun letztlich lediglich die Gedanken des Königs, wenn auch in genialer Form, umgesetzt hatte. Le Brun war Hofkünstler, Bernini war - glaubt man Chantelou - dieser Position, selbst wenn er für einen Hof arbeitete, bereits entwachsen. Und schließlich muß erwähnt werden, daß Chantelou seiner Beschreibung der Büste Ludwigs XIV. Beobachtungen zur Rezeption des Kunstwerkes anfügte und damit eine weitere neue Dimension einbrachte, die Félibien ebenfalls nicht berücksichtigt hatte. Auch wenn die einzelnen Argumentationsschritte noch nicht einer ausgearbeiteten Systematik folgen, so haben wir es doch bei Chantelous Ausführungen zur Porträtbüste Ludwigs XIV. zum ersten Mal mit einer zwar über mehrere hundert Seiten verstreuten, aber doch umfassenden Interpretation eines Kunstwerkes zu tun, die alle Bereiche von der Werkgenese über eine genaue Beschreibung und die Benennung ikonographischer Gesichtspunkte bis hin zur Rezeption einbezieht. ${ }^{31}$

Chantelous Text wurde gegen Ende des 19. Jahrhunderts erstmals publiziert, doch scheint er bereits seinen Zeitgenossen bekannt gewesen zu sein. ${ }^{32}$ Das Manuskript kursierte in den kunstinteressierten Kreisen von Paris. Und es ist nicht auszuschließen, daß es auch an der Kunstakademie wahrgenommen wurde. ${ }^{33}$ Die Neuerungen des Textes, die Beschreibung eines Werkprozesses und davon abgeleitet des künstlerischen Genies, auch die Berücksichtigung des Betrachterverhaltens, wurden indes bei dem zentralen Projekt der Académie Royale de Peinture et de Sculpture, den ab 1667 regelmäßig abgehaltenen ,Conférences ${ }^{6}$, nicht aufgegriffen. Die ,Conférences‘ knüpften vielmehr an die hier untersuchten Texte an, die sich in unmittelbarer Auseinandersetzung mit einem Kunstwerk um die Erfassung von dessen Gehalt bemühten. Der Aufbau der ,Conférences“ der ersten Serie ist immer wieder der gleiche: Ein Akademiemitglied referiert über ein Kunstwerk aus der königlichen Sammlung (mit einer Ausnahme handelt es sich um Gemälde) und filtert nach einer eingehenden Beschreibung die Regeln heraus, die die Institution für ihren Ausbildungsalltag benötigte. Wir haben es

31 Zur umfassenden Deutung der Porträtbüste vgl. im vorliegenden Band den Beitrag von Philipp Zitzlsperger.

32 Siehe Stanić 2001, S. 27-29.

33 In den Sitzungsprotokollen der Institution wird Chantelou indes nur einmal nach Berninis Paris-Aufenthalt im Zusammenhang mit der Schenkung einer vermutlich antiken Venus im November 1665 genannt, siehe Montaiglon, Anatole de (Hrsg.): Procès-verbaux de l'Académie Royale de Peinture et de Sculpture. 1648-1793. Bd. 1, Paris 1875, S. 293. 
hier mit einer neuen Form der Verschriftlichung von Kunst zu tun. Bedurften bis dahin die Kunstwerke eines Textes, um sich vollends entfalten zu können, so werden nun die Überlegungen den Werken nicht zu deren Verständnis hinzugefügt, sondern sie sind den Werken entnommen. Die Sprache formuliert lediglich das, was die Kunstwerke (allen voran die Gemälde von Raffael und Poussin) in sich bergen und was sie vorbildlich für das künstlerische Schaffen macht.

Fraglos waren die ,Conférences' auch in einen politischen Kontext eingebunden, ${ }^{34}$ dieser trat jedoch in den Hintergrund. Die Vorträge blendeten die Einbindung eines Kunstwerkes in einen Funktionszusammenhang aus, ${ }^{35}$ ließen auch inhaltliche Gesichtspunkte weitgehend unberücksichtigt und konnten sich so auf das zentrale Anliegen, die Ausformulierung von Regeln für den künstlerischen Alltag und die Entwicklung einer spezifisch französischen Kunsttheorie, konzentrieren. Die Analysen kulminierten in Henri Testelins ,Sentimens des plus habiles peintres du temps' (1680, zweite wesentlich erweiterte Auflage 1696). Kunstwerke benannte Testelin nicht mehr, sie waren nicht mehr notwendig, da man nun die Regeln zu den einzelnen Bereichen besaß: ,Sur l'usage du trait et du des$\sin ^{6}$, ,Sur l'expression générale et particulière', ,Sur les proportions', ,Sur le clairobscur', ,Sur l'ordonnance', ,Sur la couleur'.

Die Verbindung von formal-künstlerischen und inhaltlich-politischen Gesichtspunkten in den Texten Félibiens und Chantelous wurde damit vorerst nicht weiter verfolgt. Die Akademie konzentrierte sich auf die Beschreibung der künstlerischen Ebene und entzog die Kunstwerke einer politischen Vereinnahmung, der die Institution de facto unterlag. ${ }^{36}$ Aber auch auf politischer Ebene wurden die Grenzen des Konzeptes bald deutlich. Sie zeigten sich bereits frühzeitig bei der Reproduktionsgraphik nach im königlichen Auftrag entstandenen Kunstwerken. Den Graphiken wurden Texte beigegeben, die sich auf die politische Bedeutung der Werke konzentrieren. So ist der großformatige, 1663 entstandene Kupferstich von Gérard Edelinck nach Le Bruns Zelt des Darius überschrieben mit „Es gebürt einem König, sich selbst zu besiegen“37 (Abb. 6). Der erläuternde Text beschreibt die historischen Begleitumstände des geschilderten Ereignisses, nimmt aber an keiner Stelle Bezug auf die Darstellung: Alexander tritt, nachdem er Darius besiegt und die Stadt Issos eingenommen hat, in das Zelt des Darius ein, wo er dessen Mutter, Frau und Töchter vorfindet und ein einzigartiges Beispiel von Zurückhaltung an den Tag legt. Daß der Text nicht die Farbe benennt, der Félibien in seiner Beschreibung eine hohe Bedeutung beigemessen hatte, ist angesichts des Mediums der Druckgraphik verständlich, aber

34 Siehe Held, Jutta: Französische Kunsttheorie des 17. Jahrhunderts und der absolutistische Staat. Le Brun und die ersten acht Vorlesungen an der königlichen Akademie. Berlin 2001.

35 Etwaige Versuche, insbesondere aus dem Kreis um Philippe de Champaigne, die religiöse Funktion eines Kunstwerkes einzuklagen, konnten sich in den Diskussionen nicht durchsetzen. Siehe hierzu Kirchner, Thomas: Religion als Thema der Historienmalerei. In: Laufhütte, Hartmut (Hrsg.): Künste und Natur in Diskursen der Frühen Neuzeit. Wiesbaden 2000, S. 535-548.

36 Siehe dazu Kirchner 2001, S. 450-452.

37 „Il est d'un roy de se vaincre soy mesme“. 


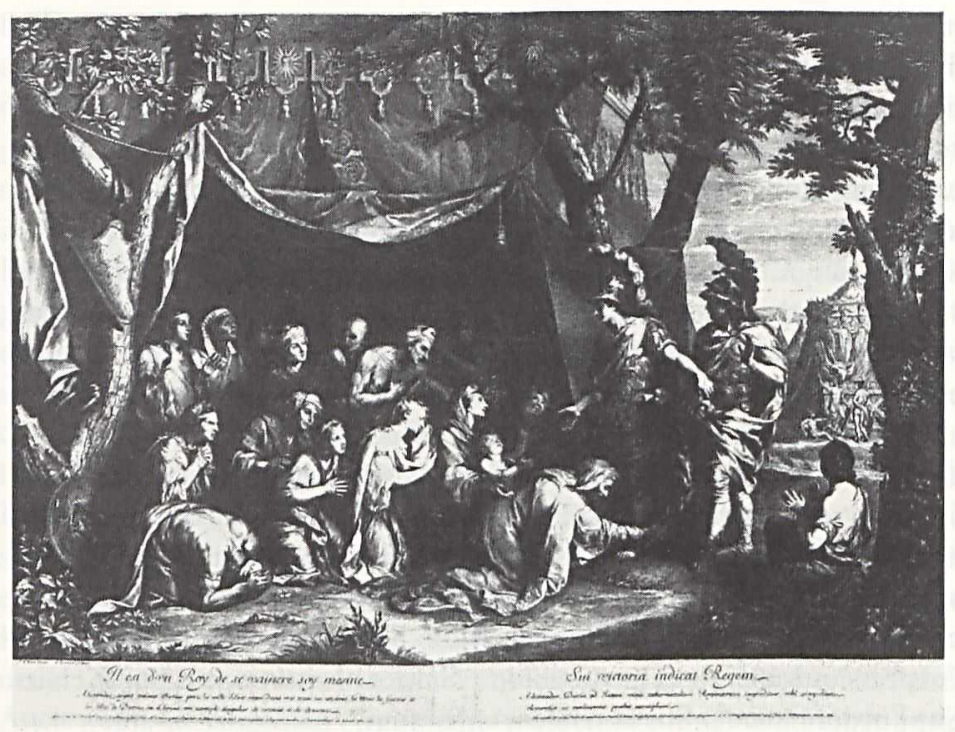

Abb. 6: Gérard Edelinck nach Charles Le Brun: Das Zelt des Darius. 1663

auch die von dem Autor herausgearbeitete künstlerische Struktur des Gemäldes, die mimischen Ausdrucksformen und das narrative Programm werden nicht erwähnt, noch nicht einmal der dramatische Höhepunkt des wiedergegebenen Momentes, in dem die Mutter des Darius aus Versehen dem falschen zu Füßen fällt und Alexander diesen Fauxpas entschuldigt. Die in der Überschrift thematisierte Herrschertugend ist wiederum nicht zentraler Gegenstand des Gemäldes. Denn die Bemerkung, daß ein König sich selbst beherrschen müsse, bezieht sich nicht auf das genannte Ereignis, sondern auf die von den antiken Historikern berichtete Geschichte, daß Alexander sich unmittelbar in die älteste Tochter des Darius Stratonike verliebte, sich in seiner Liebe aber erst einmal zurückgehalten habe.

Der Stich Edelincks ist im selben Jahr wie Félibiens Beschreibung des Gemäldes entstanden, Auftraggeber war in beiden Fällen die königliche Kulturverwaltung. Warum wird im Text die künstlerische Dimension angesprochen, in der Erläuterung der Graphik hingegen nicht? Offensichtlich haben wir es mit zwei Textsorten mit unterschiedlichen Adressatengruppen zu tun, die unterschiedlichen Gesetzen gehorchten. Der Stich war vornehmlich als diplomatisches Geschenk gedacht und mußte eine unmittelbare politische Aufgabe erfüllen, die letztlich unabhängig vom künstlerischen Wert der Vorlage ist. Das Bild hing hingegen in den Tuilerien, später im Schloß von Versailles. Und am Hofe wurde ein Werk nicht nur auf seine politische Bedeutung hin befragt, sondern es war auch Gegenstand künstlerischer Reflexion. So mußte der Höfling im Umgang mit dem Kunstwerk seine Bildung unter Beweis stellen, das Gespräch über Kunstwerke gehörte zu den Ritualen und Etablierungsstrategien am Hofe. Der in Fragen der Kunst Bewanderte zeichnete sich hierbei besonders aus. Entsprechend forderten die pädagogischen Texte der Zeit von den Erziehern der Prinzen und 
der Adeligen, ihre Zöglinge in Sachen Kunst und besonders in der Fähigkeit des gewandten Sprechens über Kunst zu unterrichten. Diese für das Leben am Hofe wichtigen Kenntnisse vermittelte Félibiens Text für Le Bruns Bild. ${ }^{38}$

So wie die Akademie in ihren ,Conférences“ die inhaltliche Dimension der analysierten Kunstwerke weitgehend ausblendete, so verzichtete die königliche Kulturverwaltung bei der Beschreibung des letzten großen Ausstattungsprojektes des 17. Jahrhunderts, Charles Le Bruns Ausmalung der Galerie des Glaces im Schloß von Versailles, auf die Benennung der künstlerischen Dimension, und dies, obwohl diese in den Werken doch unmittelbar greifbar erscheint. Die Ausmalung war auch das letzte Projekt, bei dem die Verschriftlichung eine zentrale Rolle spielte. Unmittelbar nach der 1684 erfolgten Fertigstellung der Galerie erschienen im Auftrag der Kulturverwaltung zwei Beschreibungen von François Charpentier und Pierre Rainssant. ${ }^{39}$ Le Brun knüpfte mit seiner Vermischung realer zeitgeschichtlicher Personen mit mythologischen und allegorischen Figuren auf einer Erzählebene zweifellos an Rubens' Medici-Galerie an, und auch die beiden Beschreibungen folgten weitgehend den bekannten Vorlagen. Die einzelnen Szenen werden benannt, die Figuren werden entschlüsselt, es wird aber an keiner Stelle eine darüber hinausgehende Interpretation versucht, auch bleibt die künstlerische Dimension weitgehend unberücksichtigt, Charpentier nennt noch nicht einmal den Namens Le Brun's. Die Entscheidung für eine möglichst zurückhaltende Beschreibung der Werke, die sich in einem starken Maße von Félibiens Beschreibung von Le Bruns, Zelt des Darius‘ unterscheidet, war bewußt vorgenommen worden. Die Texte sollten wie auch die in französischer Sprache abgefaßten Beschriftungen das Verständnis der Bilder sichern, sie sollten aber keine Interpretation liefern. Dies sei vielmehr Aufgabe des Betrachters. Für die Beschreibung der Werke galt auch die Überlegung, die der königliche Historiograph Nicolas Boileau im Zusammenhang mit den Inschriften anstellte: „Es ist an der Beschriftung zu sagen: ,Hier ist die Überquerung des Rheins', und der Leser wird sehr wohl ohne sie zu sagen wissen: ,Die Überquerung des Rheins ist eine der wundervollsten Handlungen, die jemals in einem Krieg geleistet worden sind. " " 40 (Abb. 7) Eine Bedeutung für die französische Kunsttheorie konnten die Texte von Charpentier und Rainssant durch den bewußten Verzicht auf die Thematisierung einer künstlerischen Dimension im Unterschied zu den Ausführungen von Félibien und Chantelou nicht haben.

38 Allgemein zu der Frage siehe Germer, Stefan: Les lecteurs implicites d'André Félibien. Ou pour qui écrit-on la théorie de l'art. In: Germer, Stefan/Michel, Christian (Hrsg.): La naissance de la théorie de l'art en France. 1640-1720. Paris 1997 (Revue esthétique 31/32, 1997), S. 259-267, hier besonders S. 263-265.

39 Charpentier, François: Explication des tableaux de la galerie de Versailles. Paris 1684; Rainssant, Pierre: Explication des tableaux de la galerie de Versailles, et de ses deux sallons. Versailles 1687.

40 „C'est à l'inscription à dire: ,Voilà le passage du Rhin', et celui qui lit saura bien dire sans elle: ,Le passage du Rhin est une des plus merveilleuses actions qui aient jamais été faites dans la guerre. “"Boileau, Nicolas: Discours sur le style des inscriptions. In: Ders., Euvres complètes (Gidel, A. Ch. Hrsg.). Bd. 3, Paris 1873, S. 265. 


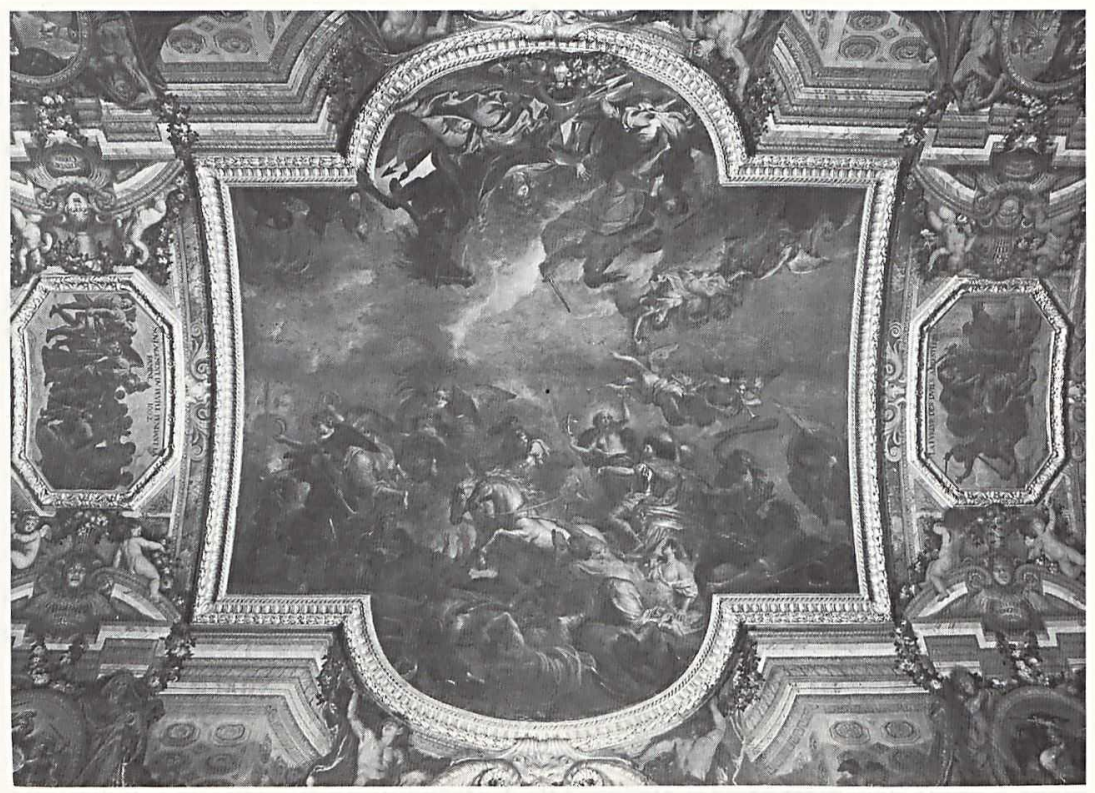

Abb. 7: Charles Le Brun: Die Überquerung des Rheins. Versailles, Musée national du château, Grande Galerie

Mit der Ausmalung der Galerie des Glaces endete eine systematische Einbeziehung der Kunst in die staatliche Selbstdarstellung. Entfiel damit in einem offiziellen Kontext die Verschriftlichung von Kunstwerken, so waren auf künstlerischer Ebene die Akademievorträge dafür verantwortlich, daß die Auseinandersetzung mit dem Kunstwerk in der Kunstliteratur keine zentrale Rolle mehr spielte. Sie wurde nun ersetzt durch die Auseinandersetzung mit der Kunst. Die Kunstliteratur war selbständig geworden, sie benötigte im späten 17. und in der ersten Hälfte des 18. Jahrhunderts das Kunstwerk nicht mehr, um ihre Ideen zu entwickeln. Erst in der Mitte des 18. Jahrhunderts sollte auf die Verschriftlichung des Kunstwerkes zurückgekommen werden. Die Historienmalerei war nach dem Rückzug des Königs als Hauptauftraggeber in eine existenzgefährdende Krise geraten, deren Behebung um 1750 mit vereinten Kräften verfolgt wurde. Das neue Kunstpublikum, das durch die Salons entstand, interessierte sich nicht mehr für die klassischen Themen, was unter anderem darauf zurückgeführt wurde, daß es diese nicht verstand. Konsequenz war - so die Reformer - eine Verflachung der Kunst, da immer wieder dieselben leicht wiedererkennbaren Themen von den Künstlern aufgegriffen wurden. Der Kunstkritiker La Font de Saint Yenne schlug zur Behebung dieses Mangels vor, die Gemälde mit einer kurzen Beschreibung der Bildthemen auf einer Kartusche zu versehen, die am Rahmen befestigt werden sollte. Auf diesem Wege könnten neue Themen eingeführt werden, ohne daß der Betrachter ermüde. Dieser sei befreit von der mühseligen Arbeit der Identifikation der Bildinhalte und könne sich so direkt dem Kern eines Kunstwerkes zuwenden, der für den Kritiker vor allem in dessen moralischer Mission 


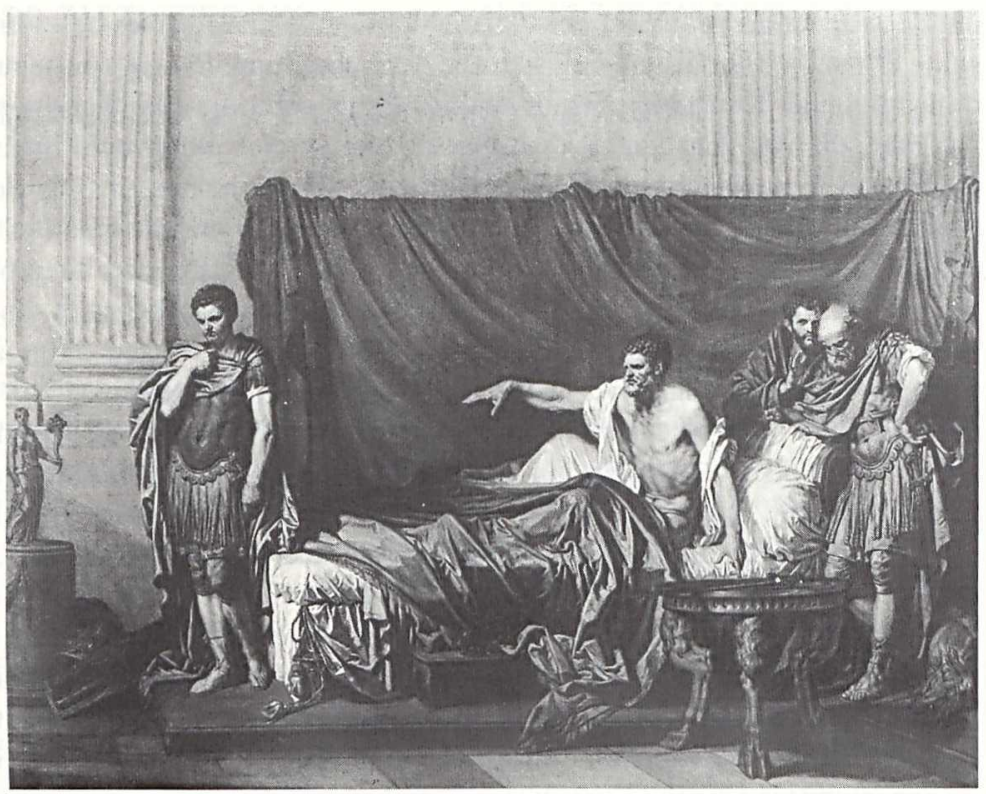

Abb. 8: Jean-Baptiste Greuze: Septimus Severus und Caracalla. 1769. Paris, Musée du Louvre

lag. ${ }^{41}$ Auch wenn der Vorschlag erst von der modernen Museumspädagogik umgesetzt wurde, so folgten die Künstler doch der Notwendigkeit einer genaueren Benennung des Bildthemas, wenn sie den Ausstellungsbesuchern immer ausführlichere Titel für ihre Historienbilder an die Hand gaben. Ein Beispiel sei lediglich genannt: Als Jean-Baptiste Greuze sein äußerst ambitioniertes Akademie-Aufnahmewerk auf dem Salon von 1769 ausstellte, nannte er das Bild nicht lediglich ,Septimus Severus und Caracalla', wie dies in früherer Zeit geschehen wäre, sondern er versah es mit einem detaillierten Titel: „Der Kaiser Septimus Severus wirft seinem Sohn Caracalla vor, ihn in den schottischen Gebirgsengen habe ermorden lassen wollen und sagt zu ihm: ,Wenn du meinen Tod wünschst, so befiehl Papinian, mich mit diesem Schwert umzubringen." "42 (Abb. 8)

Der Vorschlag La Font de Yennes war nicht neu, er griff die beschriebenen Praktiken des 17. Jahrhunderts auf, verfolgte aber andere Absichten. Befreit von den politischen Implikationen, die die Erläuterung eines Bildes durch einen Text

41 La Font de Saint Yenne: Sentimens sur quelques ouvrages de peinture, sculpture et gravure, écrits à un particulier en province. O. O. 1754, S. 111; siehe hierzu Kirchner, Thomas: Neue Themen - Neue Kunst? Zu einem Versuch, die französische Historienmalerei zu reformieren. In: Mai, Ekkehard (Hrsg.): Historienmalerei in Europa. Paradigmen in Form, Funktion und Ideologie. Mainz 1990, S. 107-120, hier S. 108-109.

42 „L'empereur Sévère reproche à Caracalla son fils, d'avoir voulu l'assassiner dans les défilés d'Ecosse, et lui dit: ,Si tu desires ma mort, ordonne à Papinien de me la donner avec cette épée. ““ 
im 17. Jahrhundert etwa bei der Galerie des Glaces in Versailles besessen hatte, sollte er nun gewährleisten, daß sich der Betrachter unabhängig von seinem Bildungsstand der Kunst nähern konnte und offen war für die inhaltlich-moralische Aufgabe, die von zentraler Bedeutung für die von den Reformern angestrebte Kunst war. Eine Beschränkung ist indes auch hier zu bemerken. Die Beschriftungen - wie umfangreich sie auch ausfielen - betrafen nur die inhaltliche Seite eines Kunstwerkes, die künstlerische blieb wie im 17. Jahrhundert ausgeblendet.

Erst die neue Gattung der Kunstkritik knüpfte an das Konzept einer umfassenden, gleichermaßen inhaltliche wie künstlerische Fragen aufgreifenden Beschreibung eines Kunstwerkes an. Sie nahm sich im Unterschied zur Kunsttheorie, die sich allgemeinen Fragen der Kunst widmete, wieder dem Kunstwerk an. Die Kunstkritik war offen für alle Fragen, die mit einem Kunstwerk zusammenhingen: die inhaltliche Deutung, die künstlerische Struktur, die Entstehungsbedingungen und die Rezeption. Nun baute die Kunstkritik sicherlich auf den Diskussionen auf, die im 17. Jahrhundert an der Akademie geführt worden waren, auch sind die kunsttheoretischen Texte von Roger de Piles und Jean-Baptiste Du Bos von zentraler Bedeutung für sie gewesen. In ihrem Bemühen, alle Aspekte eines Kunstwerkes zu berücksichtigen, scheint sie aber in Chantelous Analyse von Berninis Büste Ludwigs XIV. ihren eigentlichen Vorläufer besessen zu haben. 